\title{
The Nano-Magnetic Dancing of Bacteria Hand-in-Hand with Oxygen
}

\author{
Ayesha Talib ${ }^{1}$, Abid Ali Khan ${ }^{\mathbf{1}}$, Haroon Ahmed ${ }^{1}$, Ghulam Jilani ${ }^{2}$. \\ ${ }^{I}$ Department of Biosciences, COMSATS Institute of Information Technology, Park Road, Tarlai Kalan, 45550 \\ Islamabad, Pakistan. $;^{2}$ University of Arid Agriculture - Department of Soil Sciences Rawalpindi, Punjab.
}

\begin{abstract}
Magnetotactic bacteria are mostly microaerophilic found at the interface between oxic-anoxic zones. We report a magnetotactic bacterial strain isolated from an oil refinery sludge sample that grows aerobically in simple chemical growth medium, $9 \mathrm{~K}$. They open a new window of isolation of magnetic nanoparticles through an easy natural living system.
\end{abstract}

Key words: Magnetotactic Bacteria, Bacillus, Aerobic, Magnetosomes

*Author for correspondence: abidalikhan@ @omsats.edu.pk 
Magnetotactic bacteria (MTB) are considered as self-propelled oxygen sensors with overall sizes of only 1 to $2 \mu \mathrm{m}$ across. The cells contain chains of magnetic nanoparticles that act as magnetic nanocompasses and portray the best example of a nanoscale navigation system in nature $(1,2)$. Magnetotaxis directional control can be applied from a weak magnetic field to force the cells towards specific areas where oxygen gradient is present (3).

MTB are widespread, motile, morphologically, phylogenetically, and physiologically diverse group of ubiquitous, gram-negative bacteria with the ability to orientate and migrate along geomagnetic field lines $(4,5)$. This ability is based on intracellular magnetic structures, the magnetosomes, which comprise membrane bound nanosized crystals of magnetic iron minerals, organized into chains via a dedicated cytoskeleton and are responsible for the cell magnetotactic behavior (6).

MTB are a heterogeneous group of aquatic prokaryotes and due to their high abundance in marine and freshwater they play an important role in biogeochemical cycling of iron and other elements (7). They are ubiquitous in sediments of freshwater, brackish, marine, and hypersaline habitats as well as in chemically stratified water columns of these environments. The presence of these bacteria depends on opposing gradient of reducing and oxidizing sulfur species and oxygen. Availability of soluble iron $\left(\mathrm{Fe}^{2+} / \mathrm{Fe}^{3+}\right)$ is also the reason for their abundance in the particular environment (8).

MTB provide an interesting example for the biosynthesis of magnetic nanoparticles (MNP) in nature. Intracellular (enveloped) crystals of (magnetite- $\mathrm{Fe}_{3} \mathrm{O}_{4}$ ) magnetic nanoparticles are synthesized through a process known as Biologically Controlled Mineralization (BCM) which results in monodispersed, complex nanostructure with unique magnetic properties useful for a variety of medical and industrial applications (9-11). MTB use biomineralization proteins to produce these magnetic crystals. $\mathrm{Fe}^{2+}$ and $\mathrm{Fe}^{3+}$ are first taken up in an energy-dependent process by a periplasmic bindingprotein-dependent iron-transport system, accumulated and then rapidly precipitate in specialized sub cellular compartments, the magnetosome vesicles under chemically defined conditions $(12,13)$. These vesicles serve as nanobioreactors by providing controlled redox, $\mathrm{pH}$ conditions and supersaturating iron concentrations for biomineralization. The membrane of the magnetosome is formed by the invagination of the cytoplasmic membrane and provides a natural coating to the matured magnetic crystal (14). MTB are microaerophiles or anaerobes which prefer environment with little or no oxygen and are considered as typical example of gradient organisms that are present at oxic/anoxic interface $(\mathrm{OAI})(15,16)$. MTB play an important role in bioremediation by digesting heavy metals from toxic compounds in industrial areas.

On the basis of the aforementioned interesting properties of MTB, we have isolated aerobic bacteria from a nearby oil refinery sludge sample. To the best of our knowledge this is the first report of an MTB isolation from Pakistan.

A sludge sample was collected from a nearby oil refinery in a pre-sterilized $15 \mathrm{~mL}$ plastic tube and returned to the lab. $2 \mathrm{~g}$ of the sample was dissolved in $50 \mathrm{~mL}$ sterile distilled water and passed through a filter paper to remove the larger particles. $20 \mu \mathrm{L}$ of the filtrate was added to $15 \mathrm{~mL}$ Luria broth and incubated on a shaker at $30{ }^{\circ} \mathrm{C}$ overnight. The medium was also added Clotrimazole $(0.025 \mathrm{mg} / \mathrm{mL})$ to avoid fungal growth. $10 \mu \mathrm{L}$ of bacterial suspension from Luria broth was cultured in the $9 \mathrm{~K}$ medium (pH 2.0) (17) at $30{ }^{\circ} \mathrm{C}$ on continuous shaking (120 rpm). The growth of the bacterial was regularly catered by measuring the Optical Density (OD) of the culture at a wavelength of $600 \mathrm{~nm}$ and subsequently plotted against time. Cells were harvested during the exponential phase, washed thrice in $0.9 \mathrm{M}$ saline solution and tested for response (alignment) towards a permanent magnet. The live cells were imaged under a light microscope at 100X magnification. The bacterial cells were also Gram stained as per the standard procedure to classify them. Magnetometry 
analysis was performed in a MPMS-VSM (Magnetic Property Measurement SystemVibrating Sample Magnetometer) (Quantum Design, US). Specially designed diamagnetic containers were filled with (dried) purified bacterial cell mass and the $\mathrm{M}$-vs-H was performed at room temperature $(300 \mathrm{~K})$. The samples were centered using a magnetic field of 1000-2000 Oe.

Most of the reported MTB are microaerophilic (or anaerobic) as per their oxygen requirements $(17,18)$. This very property of these bacteria makes them difficult candidates for culture under lab conditions (13). However, the reported bacterial strain in this study is totally aerobic and thrives well in simple medium, i.e. 9k. This make them suitable candidates to exploit them for magnetic nanoparticles biosynthesis and isolation in lab conditions.

The isolated strain from an oil refinery sludge was cultured in $9 \mathrm{~K}$ (medium) a number of times to reproduce and confirm our results. It was found out that the bacterial strain was able to grow in $9 \mathrm{~K}$ aerobically at $30-32{ }^{\circ} \mathrm{C}$. Reproduced growth plots of these bacterial cells are given in Fig. 1 which shows that these cells required around 3 hours as their lag phase followed by active cell division and rapid increase in the cell number until $15^{\text {th }}$ hour. This was followed by a 2.5 hours stationary phase embarked by a balance between viable and dead cells. The toxic waste material accumulation and depletion of nutrients (to thrive) led to the decline phase of these cells 22-24 hours. The cell viability was found to be drastically reducing in the following measurements. Gram staining showed that they are gram negative rods (Inset of Fig. 1).

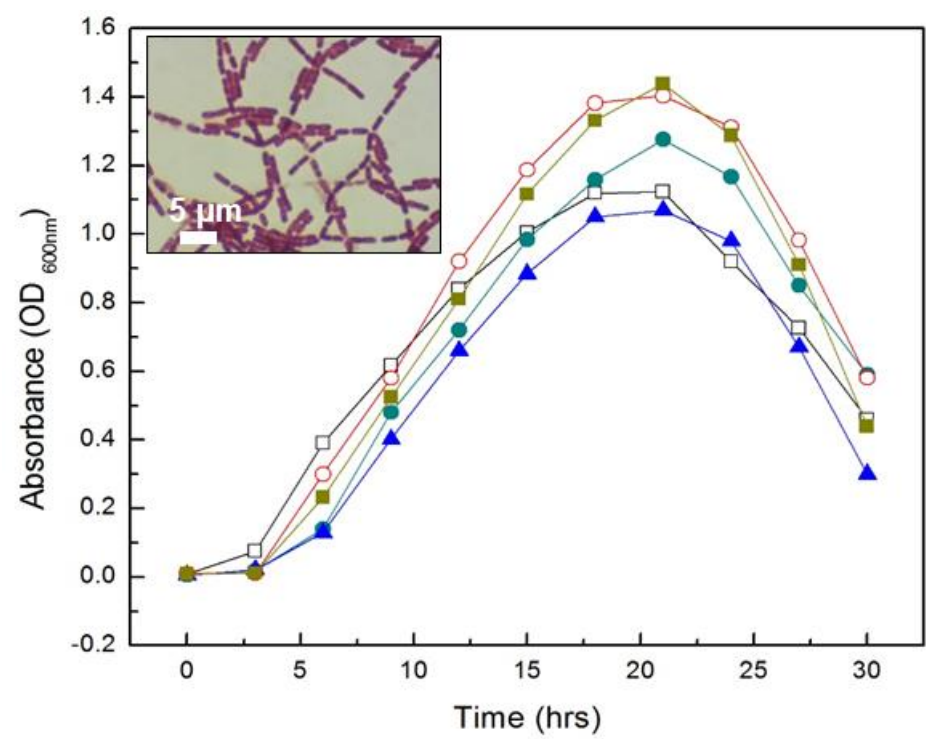

Figure 1. Reproduced growth plots of bacterial cells cultured in 9K. Inset shows a light microscopy image of the gram (negative) stained bacilli.

The bacterial cells harvested (in exponential phase), washed 2-3 times in $0.9 \mathrm{M}$ saline and a permanent magnet of strength (gradient) approximately $0.2 \mathrm{~T}$ was applied to one end of the tube to check if the bacterial cells would respond to it or not? The cultured bacterial cells upon exposure to a permanent magnet externally aligned parallel towards the field gradient (Fig. 2A). It was observed in this experimental test even by naked eye that these cells harboured magnetic content 
inside them which pushed them to swim towards the magnetic field gradient and aligned towards it. This experiment proved the fact that the bacterial cells isolated in this work are magnetic or to be precise magnetotactic. However, when $9 \mathrm{~K}$ was treated

the same way, it showed no alignment of any particles towards the magnet. This proves the fact that these bacteria have the capacity to grow in $9 \mathrm{~K}$ aerobically capable of utilizing iron ions and biosynthesize magnetosomes (magnetic nanoparticles).

As already discussed, these bacterial cells were magnetically responsive towards a permanent magnet, however, it was also noticed that these cells were not strongly magnetic but rather had a weak magnetic response, i.e. it always took them some time to swim towards the applied magnetic gradient. To investigate further the magnetism of these nanomachineries, we performed physical characterization in a VSM, i.e. magnetization was plotted as a function of the applied magnetic field at room temperature. The purified cell mass (as shown in Fig. 2A) was dried and evaluated for their magnetic properties. The aim was to check if the magnetic moment of these particles is good enough to be detected by the magnetometer. The results proved that these dried cells were superparamagnetic at room temperature $(300 \mathrm{~K})$. The hysteresis loop resulted (Fig. 2B) clearly indicated the presence of magnetic nanoparticles inside these bacterial cells. This strengthen our previous results that we had obtained with permanent magnet exposure to these cells.
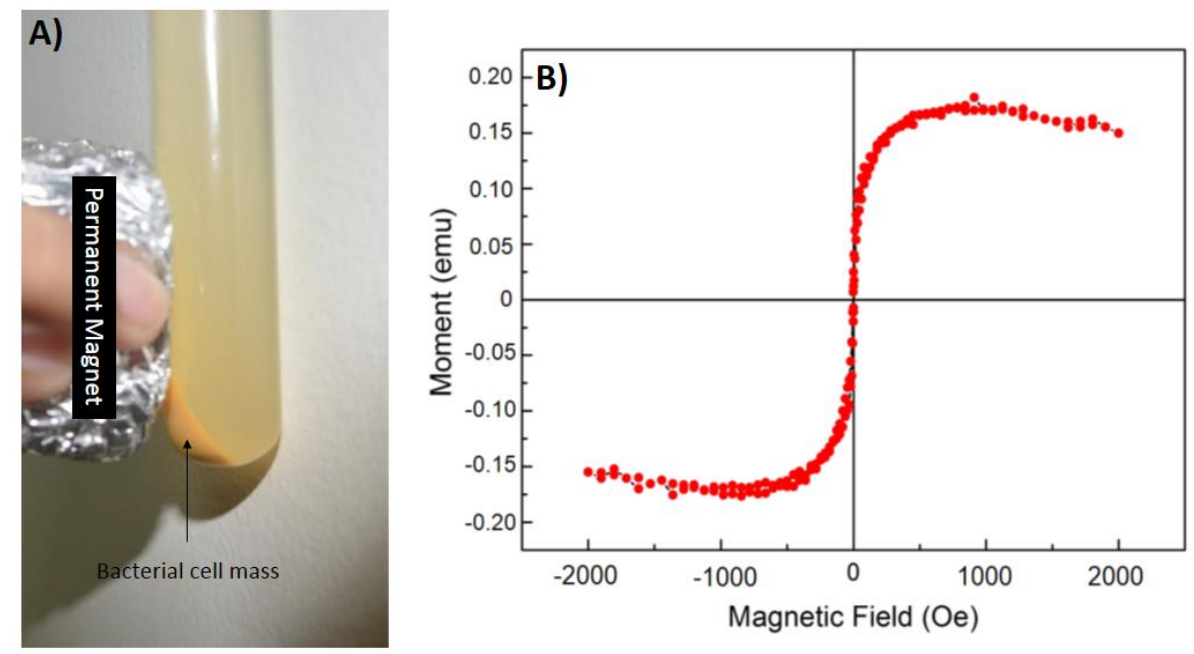

Figure 2. A) Bacterial cells swam towards the permanent magnet proving they are magnetotactic. B) Magnetization as a function of applied field of dried bacterial cell mass.

A limited published literature is available about the isolation and culture of aerobic MTB $(10,19,20)$. Matsunaga et al., isolated helical shaped MTB from fresh water sediments in a carbon medium with ferric gallate (19). Similarly, Elcey et al., and Jun et al., reported the isolation of MTB capable of thriving under aerobic conditions. They both described the isolation of rod shaped MTB; the former in $9 \mathrm{~K}$ while the latter in liquid 2219 (ferric quinate) medium $(10,20)$. It is concluded that magnetotactic bacteria capable of biomineralization under aerobic conditions do exist in our environment. There are bacterial strains capable of synthesizing magnetosomes in relatively simple growth media (such as 9K) under acidic aerobic conditions. There is a need to isolate, identify and optimize them for the synthesis of magnetic nanoparticles to replace chemically synthesized counterparts because they provide us with ease of culturing them under aerobic conditions which is way easier than either anaerobic of microaerophilic. 
Magnetotactic Bacteria as Nanobiofactories

\section{REFERENCES}

1. Wahajuddin, Arora S. Superparamagnetic iron oxide nanoparticles: Magnetic nanoplatforms as drug carriers. International Journal of Nanomedicine. 2012;7:3445-71.

2. Lin W, Bazylinski DA, Xiao T, Wu LF, Pan Y. Life with compass: diversity and biogeography of magnetotactic bacteria. Environmental microbiology. 2014;16:2646-58.

3. Martel S, Mohammadi M, Lanauze Dd, Felfoul O, editors. Magnetotactic bacteria as dispatched oxygen sensors. Sensing Technology (ICST), 2013 Seventh International Conference on; 2013 3-5 Dec. 2013.

4. Lefèvre CT, Bazylinski Da. Ecology, diversity, and evolution of magnetotactic bacteria. Microbiology and molecular biology reviews : MMBR. 2013;77:497-526.

5. Yan L, Zhang S, Chen P, Liu H, Yin H, Li H. Magnetotactic bacteria, magnetosomes and their application. Microbiological Research. 2012;167:507-19.

6. Blakemore RP. Magnetotactic bacteria. Annual review of microbiology. 1982;36:217-38.

7. Arakaki A, Nakazawa H, Nemoto M, Mori T, Matsunaga T. Formation of magnetite by bacteria and its application. Journal of the Royal Society, Interface / the Royal Society. 2008;5:977-99.

8. Mao X, Egli R, Petersen N, Hanzlik M, Liu X. Magneto-chemotaxis in sediment: First insights. PLoS ONE. 2014;9.

9. Abreu F, Cantão ME, Nicolás MF, Barcellos FG, Morillo V, Almeida LG, et al. Common ancestry of iron oxide- and iron-sulfide-based biomineralization in magnetotactic bacteria. The ISME Journal. 2011;5:1634-40.

10. Elcey CD, Kuruvilla AT, Thomas D. Synthesis of magnetite nanoparticles from optimized iron reducing bacteria isolated from iron ore mining sites. 2014;3:408-17.

11. Han L, Li S, Yang Y, Zhao F, Huang J, Chang J. Comparison of magnetite nanocrystal formed by biomineralization and chemosynthesis. Journal of Magnetism and Magnetic Materials. 2007;313:236-42.

12. Bazylinski DA, Frankel RB. Magnetosome formation in prokaryotes. Nat Rev Micro. 2004;2:217-30.

13. Schüler D. Formation of magnetosomes in magnetotactic bacteria. Journal of molecular microbiology and biotechnology. 1999;1:79-86.

14. Nudelman H, Zarivach R. Structure prediction of magnetosome-associated proteins. Frontiers in Microbiology. 2014;5:1-17.

15. Bazylinski DA, Lefevre CT. Magnetotactic bacteria from extreme environments. Life (Basel, Switzerland). 2013;3:295-307.

16. David A. Bioinspired Synthesis of Magnetic Nanoparticles. 2009.

17. Kopp RE, Kirschvink JL. The identification and biogeochemical interpretation of fossil magnetotactic bacteria. Earth-Science Reviews. 2008;86:42-61.

18. Faivre D, Schüler D. Magnetotactic Bacteria and Magnetosomes. Chemical Reviews. 2008;108(11):4875-98.

19. Matsunaga T, Sakaguchi T, Tadakoro F. Magnetite formation by a magnetic bacterium capable of growing aerobically. Applied Microbiology and Biotechnology. 1991;35(5):651-5.

20. Jun G, Hongmiao P, Haidong Y, Tao S, Yong Z, Guanjun C, et al. Isolation and biological characteristics of aerobic marine magnetotactic bacterium YSC-1. Chinese Journal of Oceanology and Limnology. 2006;24(4):358-63. 


\section{Erratum}

In Article "The Nano-Magnetic Dancing of Bacteria Hand-in-Hand with Oxygen", with DOI number: http://dx.doi.org/10.1590/1678-4324-2017160769, published in journal Brazilian Archives of Biology and Technology, vol. 60, the 01 page.

That read:

“http://dx.doi.org/10.190/1678-4324-2017160769"

Read:

“'http://dx.doi.org/10.1590/1678-4324-2017160769" 